\title{
APONTAMENTOS SOBRE A FORMAÇÃO EM REDE NO PACTO NACIONAL PELA ALFABETIZAÇÃO NA IDADE CERTA
}

\author{
LUCIANA CASTRO OLIVEIRA MACHADO ${ }^{1 ; *}$ \\ ORCID: https://orcid.org/0000-0003-4345-9391 \\ BEATRIZ DE BASTO TEIXEIRA ${ }^{1 ; * *}$ \\ ORCID: https://orcid.org/0000-0001-6864-6447
}

\begin{abstract}
RESUMO: Este artigo apresenta-se como desdobramento de uma pesquisa de doutorado que busca compreender, a partir da interlocução com agentes de formação que atuaram no Pacto Nacional pela Alfabetização na Idade Certa (PNAIC), em Minas Gerais, pela Universidade Federal de Juiz de Fora (UFJF), o processo de implementação desse programa de formação docente. A partir do referido contexto, objetiva-se analisar, a partir da apropriação dos entrevistados, os limites e as possibilidades da realização dessa política pública de governo, até o ano de 2016. Para tanto, no aspecto metodológico, o desenvolvimento do estudo se articulou à abordagem qualitativa, tendo, como instrumentos para a coleta de dados, a realização de revisão bibliográfica sobre o contexto da formação docente para os anos iniciais da Educação Básica, o levantamento documental sobre o PNAIC e, também, entrevistas semiestruturadas com agentes formativos que atuaram no âmbito da UFJF. Os dados analisados permitiram compreender que a formação pelo PNAIC foi entendida como muito relevante no cenário brasileiro, com possibilidade de acarretar melhorias na alfabetização e, portanto, garantia de aprendizagem dos estudantes. Entretanto, sendo uma formação em rede, apresentou limites voltados para aspectos como problemas estruturais referentes à força das ingerências políticas nas diferentes instâncias da rede formativa; distância entre os formadores que atuaram pela UFJF e os professores alfabetizadores que atuavam nas unidades de ensino; dificuldade de viabilização da formação de rede e, ainda, referentes à atuação dos formadores, principais responsáveis por traduzirem a política formativa. Espera-se que, além de compreender os limites e as possibilidades alusivos à formação continuada implementada pelo PNAIC por meio da opinião de coordenadores e formadores entrevistados, possa-se contribuir com elementos relevantes para a revisão e a consolidação de políticas de formação docente.
\end{abstract}

Palavras-chave: Pacto Nacional pela Alfabetização na Idade Certa. Formação em rede. Melhoria das práticas pedagógicas.

\section{NOTES ON NETWORK TRAINING IN THE NATIONAL PACT FOR LITERACY IN THE RIGHT AGE}

ABSTRACT: This article presents the results of a PhD research that seeks to understand, from the interaction with training agents who worked in the National Pact for Literacy in the Right Age (PNAIC), in Minas Gerais, by the Federal University of Juiz de Fora (UFJF), the process of implementation of this teacher training program.

\footnotetext{
${ }^{1}$ Programa de Pós-Graduação em Educação da Universidade Federal de Juiz de Fora. Juiz de Fora-MG/Brasil.

*Professora da rede municipal de Juiz de Fora. E-mail: <lu_casttro@yahoo.com.br>.

**Mestrado Profissional em Gestão e Avaliação da Educação. Professora. E-mail: <bbtbia@gmail.com> Educação em Revista|Belo Horizonte|v.36|e214853|2020
} 
Based on this context, the objective is to analyze the limits and the possibilities of the realization of this public policy of government, until the year 2016, from the appropriation of the interviewees. For that, in the methodological aspect, the development of the study was articulated to the qualitative approach, having, as instruments for the collection of data, the accomplishment of bibliographical revision on the context of the teacher training for the initial years of Basic Education, the documentary survey on the PNAIC and, also, semi-structured interviews with training agents who worked within the UFJF. The data analyzed allowed us to understand that PNAIC training was understood as very relevant in the Brazilian scenario, with the possibility of improving literacy and, therefore, guaranteeing student learning. However, being networked, it presented limits aimed at aspects such as structural problems related to the force of political interference in the different instances of the training network; distance between the trainers who worked for the UFJF and the literacy teachers who worked in the teaching units; difficulty in making the formation of a network viable and also related to the work of the trainers, who are the main responsible for translating the training policy. It is hoped that, in addition to understanding the limits and possibilities of continuing training implemented by the PNAIC through the opinion of coordinators and trainers interviewed, it is possible to contribute with relevant elements for the revision and consolidation of teacher education policies.

Keywords: National Pact for Literacy in the Right Age. Network training. Improvement of pedagogical practices.

\section{NOTAS SOBRE LA FORMACIÓN EN RED EN EL PACTO NACIONAL DE ALFABETIZACIÓN EN LA EDAD CORRECTA}

RESÚMEN: Este artículo se presenta como resultado de una investigación doctoral que busca entender, desde el diálogo con agentes de capacitación que trabajaron en el Pacto Nacional para la Alfabetización en la Edad Adecuada (PNAIC), en Minas Gerais, por la Universidad Federal de Juiz de Fora ( UFJF), el proceso de implementación de este programa de capacitación docente. Desde este contexto, el objetivo es analizar, con base en la apropiación de los entrevistados, los límites y posibilidades de llevar a cabo esta política de gobierno público, hasta el año 2016. Por lo tanto, en el aspecto metodológico, se articuló el desarrollo del estudio. al enfoque cualitativo, teniendo como instrumentos para la recopilación de datos, una revisión bibliográfica sobre el contexto de la formación docente para los primeros años de Educación Básica, la encuesta documental sobre el PNAIC y, también, entrevistas semiestructuradas con agentes de formación que trabajaron dentro del alcance de UFJF. Los datos analizados nos permitieron comprender que la capacitación de PNAIC se entendía como muy relevante en el escenario brasileño, con la posibilidad de conducir a mejoras en la alfabetización y, por lo tanto, garantizar el aprendizaje de los estudiantes. Sin embargo, como formación de red, presentó límites centrados en aspectos tales como problemas estructurales relacionados con la fuerza de la interferencia política en diferentes instancias de la red de capacitación; distancia entre los formadores que trabajaban para la UFJF y los profesores de alfabetización que trabajaban en las unidades de enseñanza; dificultad para hacer viable la formación de la red y, aún así, referirse al desempeño de los capacitadores, quienes son los principales responsables de traducir la política de capacitación. Se espera que, además de comprender los límites y las posibilidades relacionadas con la educación continua implementada por PNAIC a través de la opinión de coordinadores y capacitadores entrevistados, sea posible contribuir con elementos relevantes para la revisión y consolidación de las políticas de educación docente.

Palabras clave: Pacto nacional para la alfabetización en la edad adecuada. Entrenamiento en red. Mejora de las prácticas docentes. 


\section{INTRODUÇÃO}

Este artigo apresenta-se como desdobramento de uma pesquisa de doutorado ${ }^{1}$ que busca compreender, a partir da interlocução com agentes de formação que atuaram no Pacto Nacional pela Alfabetização na Idade Certa (PNAIC), no âmbito da Universidade Federal de Juiz de Fora (UFJF), a qual se constituiu como um centro designado pela coordenação do processo de realização do programa na região da Zona da Mata e Campo das Vertentes, no estado de Minas Gerais. Trata-se de uma pesquisa qualitativa realizada com base em levantamento documental, inventário bibliográfico sobre a temática e em entrevistas semiestruturadas com a coordenadora geral, coordenadores adjuntos e 30 (trinta) formadores que atuaram pela UFJF. Com base nesse estudo, foi possível a aproximação com aspectos do processo de implementação do PNAIC. Assim, o presente artigo tem como objetivo evidenciar e discutir alguns limites e possibilidades para a consecução dessa política de formação em rede a partir dos sujeitos envolvidos.

O PNAIC foi instituído tendo em vista a regulamentação de alfabetizar todas as crianças até, no máximo, 8 (oito) anos de idade, ou seja, ao final do $3^{\circ}$ ano do Ensino Fundamental. Apresenta-se como uma formação instituída pelo Ministério da Educação (MEC) que operou, fundamentalmente, pelas universidades a partir da articulação com os municípios pactuados. A expectativa foi de que repercutisse como uma ação capaz de potencializar a melhoria do trabalho do professor alfabetizador, viabilizando o direito à alfabetização para todas as crianças, aspecto considerado estratégico para a o sucesso escolar.

$\mathrm{Na}$ busca por situar o PNAIC no contexto mais amplo do processo formativo do professor da Educação Básica, na primeira parte deste artigo, serão tratadas as questões voltadas para a formação docente no Brasil a partir do diálogo com pesquisadores do campo da formação docente, tais como António Nóvoa, Bernadete Angelina Gatti, Elba de Sá Barreto, Marli Eliza Damalzo Afonso André, Iria Brzezinski e Magda B. Soares. Em seguida, a formação pelo PNAIC será apresentada de acordo com os documentos legais e com o mapeamento bibliográfico empreendido sobre a temática. Posteriormente, serão destacadas as percepções dos entrevistados acerca de alguns limites e possibilidades da consecução do referido programa. Por fim, serão apresentadas algumas considerações finais as quais, longe de concluírem a discussão, sintetizam aspectos de uma realidade local que, em consonância com o entendimento de Fonseca (1999), podem representar um universo maior que o da delimitação feita. Desse modo, podem ser relevantes para a revisão e a consolidação de políticas de formação para o desenvolvimento profissional docente.

\section{BREVE PANORAMA SOBRE A FORMAÇÃO DOCENTE PARA OS ANOS INICIAIS DO ENSINO FUNDAMENTAL}

Uma análise geral das produções acadêmicas sobre formação docente no Brasil (Gatti, 2008; 2013; Candau, 2003; Brzezinki, 2008; André, 2015; Gatti e Barreto, 2009) sinaliza que, passados mais de vinte anos da promulgação da Lei de Diretrizes e Bases da Educação Nacional Brasileira (LDB), Lei no 9.394/96, quando o processo formativo para a docência respaldou um profícuo debate, em especial para o magistério dos anos iniciais da Educação Básica, ainda há lacunas significativas em torno das políticas de formação do professor.

Com base nessas produções, é possível afirmar que a formação inicial recebida pelos docentes ainda costuma ser altamente teórica e com pouca atenção para a prática escolar. Além disso, a preparação em conhecimentos específicos referentes às disciplinas e conteúdos a serem ensinados e às estratégias didáticas e metodológicas voltadas para a docência dos anos iniciais ainda se mostra insuficiente. Uma amostra nacional realizada por Gatti e Barreto (2009) evidencia essa realidade. Os dados produzidos por essas pesquisadoras apontam que, na maioria dos cursos destinados à formação inicial dos professores da Educação Básica, não há disciplinas voltadas às metodologias de ensino e, quando oferecidas, são ministradas por professores que não têm conhecimento do trabalho com crianças. A disciplina de Alfabetização, fundamental na escolarização da infância, ilustra essa situação. A referida amostra indicou que, quando essa disciplina é oferecida na Pedagogia, tem à frente professores os quais, 
pela distância do cotidiano escolar, não abordam a discussão de como alfabetizar as crianças, tratando a disciplina de forma reduzida ao discurso teórico.

A vivência de Magda Soares, que desde 2007 realiza um trabalho voluntário de desenvolvimento profissional de professores e de busca de melhoria da qualidade da educação em uma rede pública de ensino de um município mineiro, respalda os dados evidenciados por Gatti e Barreto (2009).

Em Lagoa Santa, frequentemente eu me surpreendia com quanto de essencial as professoras não sabiam a respeito do processo de alfabetização e letramento, a verdadeira revelação que era para elas compreender os processos cognitivos e linguísticos que seus alunos experimentavam tentando aprender a ler e a escrever, e como as dificuldades que crianças enfrentavam eram muitas vezes geradas por ausência de um orientação adequada e pertinente que não tinham fundamentos para dar (SOARES, 2014, p. 171).

A situação retratada por Soares (2014), a partir de uma realidade local, desvela o que os estudos produzidos sobre a temática voltada para a formação docente indicam: a formação docente vem sendo pautada mais no "o quê" ensinar do que sobre o "como" ensinar (OLIVEIRA, 2010).

Em relação à formação continuada, em decorrência do preparo insuficiente dos futuros professores em sua formação inicial, vários autores afirmam a adoção de contornos de programas compensatórios (BRZEZINSKI, 2008; GAT'TI, 2008). Nessa perspectiva, tendo em vista superar as mazelas deixadas na formação inicial, tais programas centram-se nas habilidades que faltam aos docentes, tendo como base a ideia de ausência de capacidades. Sendo assim, pautam-se nos pressupostos tecnicistas de capacitação e treinamento, o que contribui, sobretudo, para o processo de desqualificação desses profissionais, ao direcionarem, de forma prescritiva, o que deve ser ensinado na escola.

Portanto, ainda que permeado por críticas quanto à incapacidade desse modelo de formação viabilizar uma formação sólida, observa-se que o processo formativo para a docência dos anos iniciais, delineado nos últimos anos, em sua maioria, não se desvencilhou do caráter prescritivo em que o conhecimento é repassado pelos formadores, em desarticulação com o trabalho que os professores em formação realizam no interior das escolas. Em decorrência disso, permanecem sendo desenvolvidas ações de formação calcadas na perspectiva de "ensinar" aos professores os procedimentos que devem ser seguidos, ao realizarem seu trabalho.

Um olhar atento para a realidade do que vem sendo oportunizado ao futuro professor revela que os dispositivos da LDB, salvo uma formação ou outra, em maioria, provocaram a remodelação do discurso, especialmente dos poderes públicos. Contudo, as formações permanecem se realizando baseadas na reprodução de modelos e na ênfase dos conhecimentos teóricos em detrimento dos do campo da prática (GATTI, 2008; 2013; CANDAU, 2003; BRZEZINKI, 2008; ANDRÉ, 2015; GATTI e BARRETO, 2009).

A concepção de um processo formativo calcado na prática como elemento constitutivo e fecundado de novos saberes ainda não se consolidou. Relevante esclarecer que, diferentemente do entendimento advindo do senso comum, esse pressuposto não restringe o sentido da prática ao entendimento de "prática pedagógica" em sala de aula, ou seja, aos procedimentos didáticometodológicos utilizados pelo professor. Desse modo, não se trata de enfatizar a experiência como elemento definidor da formação em detrimento de uma sólida formação teórica. Ao contrário, refere-se à articulação dialética entre os saberes adquiridos na ação e os saberes formalizados, de natureza teórica. Por meio dessa articulação, o "olhar" para o cotidiano pode auxiliar na produção teórica, servindo de base para o questionamento dos conhecimentos já existentes e para elaboração de novos conhecimentos práticos (RINALDI, 2012). Assim, a prática refere-se a um saber para além de saber fazer, visto que se relaciona às representações apreendidas no amplo processo de formação pessoal e profissional a partir dos saberes da experiência, da Pedagogia e das demais áreas do conhecimento. Sobre essa perspectiva, Gatti (2013) contribui ao destacar:

Se faz necessário mudar a concepção vigente sobre "prática" e "teoria”. Prática educacional é prática social em significado e não pode ser tomada como simples receita, ou confundida com tecnicismos modeladores (...) Prática pedagógica, por ser pedagógica, é ação política, de cidadania, comportando formas de ação guiadas por 
seus fundamentos, sejam filosóficos, sejam científicos. Implica fazer pensando e pensar fazendo, implica saber fazer e porque fazer, ou seja, implica uma praxiologia (GATTI, 2013, p. 55, grifos da autora).

Considerando a problemática diante da questão da falta de articulação teoria e prática no processo de profissionalização do professor, pesquisadores como Nóvoa (1991) e Canário (2004; 2006), dentre outros, ressaltam a aproximação da formação ao universo escolar. A expectativa é de que, assim, construa-se uma necessária parceria entre as escolas e as instâncias formais de formação e, por conseguinte, entre professores formadores e professores da Educação Básica, tendo em vista favorecer o diálogo entre os constructos teóricos e os do campo da atuação. Nessa direção, pretende-se, sobretudo, que essa medida seja capaz de impactar na ampliação das possibilidades de os sistemas de ensino se reestruturarem, a fim de ampliarem as condições de assegurar o sucesso escolar dos alunos a que atendem. Concomitantemente, espera-se, ainda, que as instâncias formativas, em especial a universidade, tenham bases sólidas para reestruturarem os processos formativos destinados ao desenvolvimento profissional docente.

\section{UM OLHAR NA FORMAÇÃO CONTINUADA DOCENTE PELO PACTO NACIONAL NA IDADE CERTA}

Como já mencionado na introdução, o PNAIC foi instituído com o objetivo principal de garantir o direito de alfabetização plena a todas as crianças até oito anos de idade, ao final do $3^{\circ}$ ano do Ensino Fundamental. Apresenta-se como uma ação que reafirma o que propõe o plano de metas Compromisso Todos pela Educação, previsto no Decreto no 6.094/2007a, especificamente no tocante à responsabilidade dos entes governamentais de "alfabetizar as crianças até, no máximo, os oito anos de idade, aferindo os resultados por exame periódico específico". Uma das estratégias para a consecução desse objetivo pautou-se na formação continuada dos professores alfabetizadores, incluindo os que atuavam em salas multisseriadas. O principal objetivo dessa formação foi o de apoiar todos os professores no planejamento das aulas, na definição de processo de avaliação e acompanhamento das aprendizagens das crianças do ciclo de alfabetização e na utilização dos materiais ofertados pelo MEC. Portanto, pode ser reconhecida como uma iniciativa que buscou potencializar a melhoria da prática docente na busca por reverter a "[...] dura realidade de constatar que muitas crianças têm concluído sua escolarização sem estarem alfabetizadas” (BRASIL, 2015, p. 10).

A formação instituída pela Portaria n ${ }^{\circ}$. 867, de 4 de julho de 2012b, e lançada pelo MEC em 8 de novembro de 2012 passou a ser implementada na realidade brasileira em 2013, embora algumas universidades tenham iniciado a formação ainda em 2012. Essa foi a situação da UFJF que iniciou a realização da formação como uma das instituições "pioneiras", portanto, no ano de 2012. O programa foi implementado até o ano de $2016^{2}$ por meio de uma rede articulada entre o governo federal, as Instituições de Ensino Superior (IES) e as Secretarias de Educação dos estados, do Distrito Federal e dos municípios que aderiram ao Plano de Ações Articuladas (PAR), tendo em vista a política para a alfabetização nacional. No interior dessas instâncias, conjugou-se o envolvimento de diferentes atores os quais, em articulação, desenvolveram a formação.

De acordo com os documentos que orientaram o programa em sua versão inicial (BRASIL, 2012a; 2012b), coube ao MEC definir o conteúdo de formação junto às IES; promover a parceria entre as IES e os sistemas de ensino; conceder bolsas de estudos ${ }^{3}$ aos envolvidos com o Programa via Fundo Nacional de Desenvolvimento da Educação (FNDE); elaborar, disponibilizar e manter o funcionamento do Sistema Informatizado de Gestão e Monitoramento do Pacto Nacional pela Alfabetização na Idade Certa - SisPacto; oferecer diretrizes e apoio para o desenvolvimento do programa junto às IES. Estas, por sua vez, tinham como responsabilidade toda a gestão pedagógica e acadêmica da formação dentro do âmbito de sua responsabilidade. Para tanto, suas ações foram estruturadas por meio do coordenador geral, coordenador adjunto, supervisor e formador, além de contar com uma esquipe de apoio técnico, responsável pela infraestrutura da formação em cada universidade (BRASIL, 2012a). O coordenador geral, em conjunto com os coordenadores adjuntos, atuou tendo como principais responsabilidades o monitoramento, a autorização de bolsa e a implementação de toda a atividade formativa do programa. Os supervisores tinham, como principal atribuição, dar suporte aos formadores que atuaram junto à IES 
e aos formadores que representaram os sistemas de ensino. Assim, atuaram como um importante elo entre a principal instância de formação, sendo considerados os principais responsáveis pela tradução e interpretação da proposta junto às redes escolares (ALFERES; MAINARDES, 2018). Desse modo, assumiram a tarefa da formação dos orientadores de estudo dos sistemas pactuados, acompanhando o trabalho, juntamente com os supervisores.

Importante destacar que, de acordo com a orientação legal da Portaria no 1.458 , de 14 de dezembro de 2012a, um dos critérios possíveis de serem adotados na seleção do formador foi a experiência na alfabetização. Essa condição viabilizou que a figura do professor com o crivo da experiência integrasse a universidade, o que pode ter denotado ao PNAIC um caráter inovador. Desse modo, com base nos dados que vêm sendo produzidos na pesquisa de doutoramento em processo, os quais deram origem a este artigo, tratou-se de um programa que trouxe a possibilidade de alterar o modelo comumente praticado tanto na formação inicial quanto na continuada, o qual é marcado em grande parte das situações, pela distância entre a teoria e a prática ao ter à frente, inclusive, formadores que representaram professores com prestígio acadêmico e pouca ou nenhuma vivência da realidade escolar (OLIVEIRA, 2010; NÓVOA, 1991; CANÁRIO, 2004, 2006). Assim, ter o professor com o crivo da experiência pode ser um elemento importante na busca pelo diálogo teoria e prática no processo formativo.

Ainda sobre as atribuições para o desenvolvimento do programa, os sistemas de ensino tiveram, como principal tarefa, o gerenciamento e a assistência da formação em seu âmbito de atuação. Nessa esfera, a realização do programa ocorreria por meio do coordenador local (CL), do orientador de estudo (OE) e do professor alfabetizador (PA). Coube primordialmente ao CL, profissional selecionado pela Secretaria de Educação, a coordenação das atividades, a avaliação dos OEs, a interlocução com a IES formadora e o aperfeiçoamento das ações pedagógicas no sistema de ensino que representava. Ao OE coube a responsabilidade de conduzir a formação no âmbito do seu sistema de ensino junto aos PAs. Estes, por fim, assumiram o compromisso de estudar, de se envolver nas atividades presenciais e de se empenhar para planejar, desenvolver e avaliar suas práticas a partir da reflexão dos saberes construídos e ressignificados pela formação.

Foram centrais, nos primeiros quatro anos ${ }^{4}$ de implementação do programa, os materiais distribuídos pelo MEC, com destaque para os Cadernos de Formação, principal material de apoio para as discussões. Esses Cadernos foram elaborados pelo Centro de Estudos em Educação e Linguagem (CEEL), sob a coordenação da Universidade Federal de Pernambuco (UFPE), em diálogo com professores da Educação Básica. Guardadas algumas críticas mencionadas por pesquisadores, como Luz (2017), Ferreira e Fonseca (2017), Pereira (2017), dentre as quais se destaca o entendimento de que esses Cadernos se constituiriam como um instrumento a serviço de uma orientação curricular nacional e a impossibilidade de se garantir a interlocução com os diversos atores sociais envolvidos na formação, tais materiais podem ser considerados um elemento importante da proposta formativa em questão, tendo em vista oferecer subsídios para a formação continuada de professores alfabetizadores, considerando a importância da boa preparação desses profissionais do ensino.

Nos anos de 2012-2013, foram trabalhados os Cadernos de Alfabetização em Língua Portuguesa; no ano de 2014 e no início de 2015, foram trabalhados, em consonância com o material de Língua Portuguesa, os Cadernos de Alfabetização Matemática na Perspectiva do Letramento; em 2015 e 2016, o programa foi ampliado para as demais áreas do conhecimento, de forma integrada. Contudo, 2015 foi um ano em que houve significativos cortes nas verbas destinadas à educação, o que impactou no atraso da formação. Desse modo, foi decidido, no fórum dos coordenadores gerais do PNAIC, que, no ano de 2015, seriam trabalhados os três primeiros Cadernos e o restante, no ano de 2016.

Pesquisadores que tiveram o PNAIC como foco de estudo, como Alferes e Mainardes (2019); Gelocha e Corte (2016), assim como os entrevistados desta pesquisa destacaram que os Cadernos se constituíram como importante referencial para uma base sólida de elementos fundamentais a serem estudados na formação. O entendimento é que contribuíram com melhorias na condução do ensino do processo de aquisição do sistema de escrita alfabético, oportunizando, para os alfabetizadores, condições mais seguras de planejamento e estabelecimento de ações pautadas em práticas de letramento. Assim, de 
um modo geral, os estudos realizados a partir dos Cadernos impactaram a prática pedagógica alfabetizadora, contribuindo para a compreensão dos processos de alfabetização e letramento.

Estruturado até 2016 como um curso presencial ${ }^{5}$, em linhas gerais, o PNAIC foi uma proposta de colaboração do MEC, das secretarias de ensino, da universidade e da escola, evidenciando uma ação em rede. Percebe-se que o desenho do programa previa que todas as pessoas envolvidas, afinadas em relação à teorização da prática, atuassem, de alguma maneira, na formação que chegou até a escola. Essa questão, associada à abrangência do número de professores envolvidos e ao caráter de continuidade política no território brasileiro - visto que teve como precursor o Pró-Letramento ${ }^{6}$, o que pode denotar amadurecimento e revisão de procedimentos -, sinalizam a possibilidade de impacto do programa. Além disso, com base nos dados que vêm sendo produzidos com a pesquisa de doutoramento que deu base a este artigo, percebe-se que o fato de ter permanecido por 4 (quatro) anos consecutivos na realidade brasileira parece incidir no acúmulo de importantes conhecimentos para a urgente e necessária revisão dos processos de formação docente. Com efeito, o programa pode ter potencializado as chances de provocar mudanças nas práticas docentes, de modo a acarretar melhorias na qualidade ${ }^{7}$ da educação oferecida pelos sistemas de ensino brasileiro.

\section{FORMAÇÃO DOCENTE PELO PNAIC: UMA REFLEXÃO A PARTIR DOS AGENTES FORMATIVOS DE UMA REALIDADE MINEIRA}

Tendo em vista atingir o objetivo de trazer reflexões acerca da formação em rede instituída pelo PNAIC no âmbito da UFJF, serão apresentados dados coletados por meio de entrevistas semiestruturadas com 30 (trinta) dos 32 (trinta e dois) formadores que atuaram na implementação do programa. A busca por dialogar com todos os formadores que atuaram vinculados a essa instituição ocorreu pelo desejo que a pesquisa contemplasse um universo bastante abrangente. Contudo, do número total de formadores, dois deles não deram retorno ao convite feito para integrar o estudo.

Além dos formadores, os dados aqui apresentados foram construídos a partir do diálogo com a coordenadora geral e coordenadores adjuntos do programa. Pretendeu-se, com essa estratégia, entender a expectativa desses profissionais, considerando, sobretudo, a relação que estabeleceram com os professores da Educação Básica por meio dos formadores e com as diferentes instâncias da rede formativa - MEC e sistemas de ensino - para a organização dos momentos de formação.

Todas as entrevistas realizadas foram gravadas, transcritas e tratadas a partir da análise de conteúdo de Bardin (2009). Com base nelas, foi possível perceber aspectos que se sobressaíam e muitos que se relacionavam, o que favoreceu o desenho das impressões que os entrevistados apresentaram acerca da implementação do PNAIC na realidade em que atuaram e, assim, destacar alguns limites e possibilidades para a realização dessa política pública de governo.

O grupo de formadores entrevistados foi constituído por 27 (vinte e sete) pessoas do sexo feminino e 3 (três) do sexo masculino. O grupo de Língua Portuguesa (LP) foi formado, ao longo dos anos de 2012-2016, por 19 (dezenove) pessoas exclusivamente do sexo feminino. Desse número, 18 (dezoito) eram professoras com o início da carreira marcado por um tempo na docência da Educação Infantil ou nos anos iniciais do Ensino Fundamental. Dentre os três formadores do sexo masculino, somente um deles tinha experiência no ciclo de alfabetização. Em conjunto com outras 8 (oito) formadoras, esses três atuaram na equipe da Matemática (MT), totalizando um grupo de 11 (onze) formadores nessa área de atuação. É possível observar que 4 (quatro) docentes atuaram como formadores sem terem a vivência dos anos iniciais de alfabetização. Segundo estes, isso foi um fator de muita insegurança. Acreditam que isso tenha levado, inclusive, um formador, também sem experiência nos anos iniciais, a pedir desligamento um dia antes que a formação com os OEs tivesse início. Fato que fez com que o grupo da Matemática tivesse 11 (onze) formadores e não 12 (doze), como era o previsto.

Os 4 (quatro) formadores afirmaram que observavam os colegas com experiência nos anos iniciais terem mais desenvoltura para conduzirem a formação. Chegaram a essa conclusão tanto pelas conversas estabelecidas ao longo da formação quanto pelo acompanhamento da formação pelos pares. Isso porque, na atuação pela UFJF, houve a prática de organização de duplas entre os formadores de MT e de LP. Foi combinado que parte da formação presencial aconteceria a partir da estratégia de docência compartilhada, ou seja, com ambos da dupla em sala. 
Interessante destacar ainda que ter um grupo de formadores majoritariamente do sexo feminino parece refletir a realidade do quadro do magistério dos anos iniciais do Ensino Fundamental, confirmando a tese de feminização da docência, como constatou Gatti (2010).

Em relação à formação inicial para o exercício da docência, do total dos 30 formadores entrevistados, 21 (vinte e um) cursaram o Magistério de $2^{\circ}$ grau. Desse total, 2 (dois) cursaram Letras na graduação, 1 (um) cursou Matemática, 1 (um) Psicologia, os outros 17 (dezessete) cursaram Pedagogia. Dos 9 (nove) que não fizeram Magistério, 3 (três) formadores fizeram Pedagogia, totalizando 20 (vinte) o número de pedagogos no grupo de formadores. Outros 3 (três) se graduaram em Matemática, 1 (um) em Educação Artística, 1 (um) em Psicologia e 1 (um) em Ciências Sociais.

No que se refere à decisão de se tornarem professores, 14 (quatorze) formadores declararam que o ingresso no magistério fora feito como primeira opção. No entanto, a metade desse quantitativo, no decorrer da entrevista, demonstrou que essa decisão não foi tomada livre de pressões, como as que se referem à classe social de origem. Nesse caso, viam o magistério como uma formação capaz de lhes garantir uma ocupação formal no mercado de trabalho de forma rápida. Assim, apenas 7 (sete) formadores parecem, de fato, terem tido à docência como uma opção. Os outros 16 (dezesseis) entrevistados afirmaram, de forma direta, decidirem pela docência demonstrando que essa não fora sua primeira opção. Esses dados ratificam o que outras pesquisas já apontaram sobre a baixa atratividade da profissão docente no cenário brasileiro (CRUZ, 2017; GATTI, et al., 2011; ANDRÉ, 2015). Portanto, reafirmam a necessidade de ações políticas que possam atrair, desenvolver e recrutar bons profissionais. Em comum a todos os que não tinham o magistério como uma primeira opção, consta o encontro com a docência ainda no momento inicial da formação. Marca esse encontro a possibilidade de transformarem realidades, o que denota o compromisso político de ser professor.

Os formadores entrevistados, com exceção apenas da formadora Luíza ${ }^{8}$, constituíam um grupo de professores e professoras concursados, com vínculo efetivo na rede pública de ensino. Do conjunto total, 5 (cinco) atuavam concomitantemente na rede privada de ensino. O tempo de exercício profissional no magistério era bastante variado, embora a maioria tivesse mais de 20 (vinte) anos de efetivo exercício. O quadro abaixo, construído com base nas entrevistas, ilustra essa constatação.

Quadro 1: Tempo de atuação no magistério

\begin{tabular}{|c|c|}
\hline Tempo de atuação & Total de formadores \\
\hline Menos de 10 anos & 1 \\
\hline De 10 a 20 anos & 8 \\
\hline De 21 a 30 anos & 16 \\
\hline Mais de 31 anos & 5 \\
\hline
\end{tabular}

Fonte: elaboração da autora com base nos dados das entrevistas realizadas com os formadores.

Em consonância com Tardif (2002), a dimensão temporal vivida pelos formadores pode implicar um maior domínio do trabalho, já que o tempo de atuação da maioria do grupo em questão pode representar amadurecimento no enfretamento aos desafios da carreira.

No entanto, infelizmente, constatou-se que o grupo com maior experiência profissional e, em especial, o que apresentava uma vasta vivência na alfabetização encontrava-se afastado da regência de turmas de alfabetização ou dos anos iniciais do Ensino Fundamental. Ao que parece, o tempo no magistério garante uma variedade de opções que possibilita a escolha por outras ocupações pedagógicas, tirando de cena os professores mais experientes da regência de sala de aula nos anos iniciais. Muitos dos formadores nessa situação, no período em que as entrevistas foram realizadas, encontravam-se exercendo cargos técnicos na Secretaria de Educação do município em que tinham vínculos profissionais, na direção de escolas, em salas de atendimentos especializados, como é o caso dos que atuam nos Centros de Atendimento Educacional Especializado ${ }^{9}$ (CAEE) ou haviam ingressado na docência do Ensino Superior. 
Os dados indicam, ainda, que o grupo de formadores que atuaram junto a UFJF no período da $1^{\text {a }}$ versão do PNAIC era bastante qualificado em termos de titulação. Das 30 (trinta) pessoas entrevistadas, 22 (vinte e duas) tinham feito especialização e mestrado e 10 (dez) eram doutores ou doutorandos.

Em virtude disso, supõe-se que a titulação, associada à significativa experiência profissional, possa ter fortalecido a abertura de novas frentes de trabalho. Além dos fatores antiguidade e formação, a realidade de afastamento da regência está relacionada com uma função cujos salários são pouco atrativos e as condições de trabalho são deficitárias, sendo comum o enfrentamento de problemas relacionados ao excessivo número de alunos em sala de aula e à precária infraestrutura das escolas em que atuam.

Em linhas gerais, quer seja por questões que podem estar vinculadas ao amadurecimento profissional, quer seja pela falta de valorização e incentivo para permanecerem no campo de atuação, esses profissionais optaram por atuar em outras frentes que não a sala de aula. Essa situação foi evidenciada por Vaillant (2002), não sendo uma ocorrência específica desse grupo entrevistado. A questão é que ela instaura a existência de um círculo negativo que afasta os docentes mais experientes e bem formados da realidade em que mais são necessários. Assim, perde-se o investimento feito para qualificar o profissional, as crianças perdem a oportunidade de terem um professor com conhecimento e experiência acumulada para auxiliá-las em suas aprendizagens, perde-se a possibilidade de as propostas formativas calcadas na escola terem suas chances ampliadas de sucesso. Dessa forma, além do fato de se diminuírem as chances de mudanças na cultura escolar, evidencia-se um desperdício de dinheiro público.

Entre os formadores entrevistados, pode-se afirmar que essa realidade só não tomou proporção maior porque 7 (sete) formadoras eram professoras do Colégio de Aplicação da Universidade Federal de Juiz de Fora - Colégio João XXIII, local em que as condições de trabalho, a valorização, tanto salarial quanto de formação, são bastante diferentes das vivenciadas pela maioria dos professores da rede pública municipal e estadual de ensino de Minas Gerais. A fala da formadora Joana, professora no Colégio de Aplicação da UFJF, ilustra isso:

Eu acho que, se eu tivesse em outra rede pública, talvez eu não estaria na sala de aula. Porque tem uma questão de desgaste físico, uma questão natural da idade, do cansaço e junto com isso do pouco investimento no professor. Eu estou em lugar que me dá todas as condições de fazer um bom trabalho. Então é óbvio que o lugar onde estou é muito responsável também, as condições que eu tenho de trabalho (...) A gente tem condições de trabalho que deveriam e poderiam ter em outras redes públicas. Tenho bolsista, tenho 20 (vinte) alunos em sala, tenho trabalho coletivo. Tem uma estrutura de gestão e de coordenação que ajuda. O salário não é o que eu queria, mas também não posso dizer que é um salário que qualquer outro professor ganha. Colegas meus, que têm um trabalho tão bom quanto, ou melhor, que estão aí trabalhando em três, quatro lugares. Afinal aqui eu tenho 40 horas e dedicação exclusiva e sou paga por isso. Sinto que tenho que dar retorno a isso tudo. Com certeza, tenho esse compromisso (JOANA - formadora de LP e de MT ${ }^{10}$ pela UFJF).

A declaração da formadora retrata o que comumente é defendido nos meios acadêmicos e pelas entidades representativas do magistério sobre a necessidade de consolidação de uma política de valorização do magistério que atrele a política de formação às condições de trabalho e de remuneração. André (2015) trata dessa discussão como uma questão central no seio das políticas de valorização do trabalho docente no Brasil. Para ela, faz-se urgente a adoção de políticas que possam articular condições para que os docentes queiram permanecer no exercício da função na escola e na profissão. A expectativa é de que somente a adoção de um conjunto de medidas para além da formação continuada favorecerá melhorias no ensino.

A necessidade de continuar investindo na própria formação foi outro ponto comum mencionado nos depoimentos dos formadores. Em geral, a maioria deles parece ter se mantido em constante formação, quer seja por meio de cursos oferecidos pela administração pública, quer seja por iniciativa própria. Segundo eles, o envolvimento em diferentes oportunidades formativas, ao longo da carreira, relacionou-se, inicialmente, à busca de conhecimentos para suprir as lacunas da formação inicial que tiveram. Com o tempo, deu-se pelo desejo constante de construir melhores formas de realizar o ofício docente. Com efeito, os profissionais sinalizam o entendimento da formação continuada para além dos preceitos tecnicistas de capacitação e treinamento. Nessa direção, consoante a perspectiva de Freire (1996), o processo formativo para eles é pautado em um movimento incessante de busca e pesquisa. 
Sobre os formadores entrevistados cabe destacar, ainda, que se tratava de um grupo com significativa experiência como formadores anterior à atuação no PNAIC. Essa foi a realidade de 21 (vinte e um) formadores. Ao serem indagados sobre como ocorrera a aprendizagem para atuarem como formadores, afirmaram que haviam construído saberes ao longo da trajetória formativa e profissional. Dessa forma, constituíram-se como formadores na relação com seus alunos, com os colegas professores e com seus próprios formadores.

Em relação às considerações que teceram especificamente acerca da formação pelo PNAIC, destacaram, inicialmente, o entendimento de que, a despeito de o modelo de formação em rede receber críticas da comunidade acadêmica - sobretudo por se orientar por um modelo de formação em cascata, no qual um primeiro grupo de profissionais é capacitado para organizar e repassar o conteúdo formativo, assumindo a função de capacitador de um novo grupo (Gatti e Barreto, 2009), fortalecendo, assim, o caráter prescritivo que negligencia o saber do professor em formação -, não perceberam essa perspectiva restrita de formação na realidade em que atuaram. Dito isso, mencionaram que, por se estruturar como uma formação em rede, o PNAIC teve como desafio a distância com os PAs. Destacaram que esse fator não afetou o esforço que empreenderam em propiciar a reflexão dos professores sobre o seu fazer pedagógico a partir do diálogo com os OEs. Assim, buscaram, por meio desses representantes dos municípios da Zona da Mata mineira e Campo das Vertentes, articular a proposta do curso com a prática pedagógica. O grupo afirmou ainda que, mediante a formação desses agentes, o PNAIC propiciou aos sistemas de ensino constituir uma rede de formadores, viabilizando a movimentação das redes de ensino incorrendo na implementação da formação de rede.

Sobre a formação continuada em rede e de rede, importante esclarecer a distinção evidenciada pela mudança de proposição. Em concordância com Soares (2014), a formação em rede refere-se à

(...) articulação entre o Ministério da Educação (MEC), as universidades e os municípios que, organizando-se em uma rede, oferecem cursos aos professores em exercício. É uma rede que na verdade institui certa hierarquia, tendo o MEC no topo, em seguida as universidades, a quem o MEC propõe que assumam os cursos segundo normas estabelecidas em editais, e, por fim, os municípios, aos quais são oferecidos os cursos (SOARES, 2014, p. 149).

Diferentemente, ainda de acordo com a pesquisadora,

$\mathrm{Na}$ formação de rede não há organização hierárquica. Pretende-se que a rede se constitua como uma coletividade, um conjunto de pessoas com os mesmos compromissos, tentando alcançar os mesmos objetivos, se esforçando na mesma direção. A formação de rede atinge a rede de ensino inteira: todos os professores, todos os gestores, todos os profissionais que atuam em todas as escolas, com o objetivo de promover o avanço na qualidade do ensino em todas as escolas igualmente, e no mesmo ritmo (IDEM, p. 150).

Considerando essa distinção dos termos, os formadores afirmaram que tinham como expectativa que, a partir da interlocução com os OEs, o programa fomentasse a formação de rede, ou seja, uma formação organizada pelos sistemas de ensino de cada localidade oportunizando a participação de todos os professores. Além disso, entendiam que essa formação deveria ter como referência as demandas por eles apresentadas, tendo em vista o desenvolvimento do processo de ensino-aprendizagem. Por tudo, o contexto favorável que os formadores percebiam a respeito das possibilidades formativas instituídas pelo PNAIC demandava, segundo a ótica deles, o envolvimento das partes que constituíam a rede de formação. Nessa percepção, o rompimento de um elo da rede afetava toda a estrutura da proposta, trazendo prejuízos à implementação do programa. Sobre isso destacaram as vulnerabilidades percebidas nas diferentes instâncias.

No caso do MEC, destacaram o atraso na entrega de materiais e no pagamento das bolsas; a indefinição pela continuidade do programa, situação comum no término de cada formação realizada ao longo desses anos de existência do PNAIC; o reinício das atividades formativas no meio ou final do ano letivo, situação que fez com que o PNAIC fosse "encaixado" de forma quase que atropelada no meio das agendas profissionais e pessoais dos atores envolvidos. A respeito desse último aspecto, importante considerar que a sobrecarga de trabalho, como uma realidade vivenciada pelos formadores e que reflete 
a da maioria dos professores brasileiros, devido, normalmente, às questões financeiras do magistério, foi o fator apontado como o que os levou a atuarem em condições pouco confortáveis. Esse cenário reforça a urgência de uma política de valorização do magistério e, em especial, indica a necessidade de se pensar em uma proposta de trabalho para o formador. Em decorrência disso, alguns formadores sugeriram a garantia da redução do tempo de trabalho na rede em que têm vínculo, durante o período em que os professores estiverem à frente de uma formação. Essa medida facilitaria o tempo de investimento necessário para estudo, deslocamento e planejamento da formação, amenizando um dos maiores problemas apontados pelos formadores diante da atuação no PNAIC.

No âmbito das universidades, os formadores apontaram, como uma das vulnerabilidades no desenvolvimento do programa, a falta de unidade na formação. Ilustra essa situação o excerto de Aline, formadora que atuou no âmbito de outra instituição, antes de constituir o grupo de formadores da UFJF. A formadora mencionou que, pautado em um discurso que clamava pela autoria das formadoras, a coordenação destacava que o PNAIC não poderia ser

\footnotetext{
"receita de bolo". Nem para nós formadoras e nem nós podíamos dar "receita de bolo" para as OEs. Portanto, a coordenação deixava claro que era importante que cada uma de nós montássemos a formação de acordo com a nossa vivência na turma. Porque a universidade não teria que tratar a gente, como quem teria que seguir modelos. Como resultado, cada uma falava de um assunto, a partir do entendimento pessoal e pronto. Assim, não tinha muito critério para desenvolver a formação. Isso gerou um grupo pouco coeso (ALINE - formadora do PNAIC na área de LP pela UFJF).
}

Ao que parece, o temor em dar um tom prescritivo à formação pode ter levado à negligência de um trabalho da coordenação da IES junto aos formadores, tendo em vista manter a unidade na condução do grupo de PAs. Os formadores comungaram da opinião que, em uma realidade com lacunas na formação inicial, como já mencionado anteriormente, deixar a formação seguir sem uma orientação precisa, fora, no mínimo, perigoso. Destacaram a importância da condução do grupo de formadores ser calcada na construção coletiva, na deliberação consensual do grupo com o propósito de fortalecê-los e de criar uma identidade para a formação.

Além disso, mencionaram que, pela própria trajetória formativa que vivenciaram (e vivenciam), ter um formador com estofo teórico, experiência no campo escolar e boas estratégias didáticas são variáveis importantes, mas nem sempre comuns a todos os formadores que atuam frente a uma formação. Sendo assim, entendiam que, longe de "dar receita de bolo", a atuação da coordenação junto aos formadores constituiria uma ação que precisava ser tomada, a fim de se garantir uma base comum e necessária aos que atuavam como os principais agentes formativos, de modo a terem aumentadas suas chances de provocar a desestabilização de práticas equivocadas ou improdutivas instituídas na cultura escolar.

Portanto, o grupo foi unânime em afirmar a importância da Universidade em garantir espaço para a formação e planejamento coletivo para os encontros com as OEs. Especificamente. os 4 formadores que não apresentavam vivência nos anos iniciais de escolarização afirmaram que esse espaço fora fundamental para se aproximarem um pouco mais do universo dos seus pares, os PAs. Mencionaram que, por terem condições de diálogo com os colegas formadores, sentiram condições de articular as temáticas de estudo ao contexto escolar. Por fim, alegaram que, se não tivessem a garantia desse momento, talvez tivessem desistido da função.

O fato é que foi comum aos 30 formadores a certeza de que essa fora uma ação indiscutível para se apropriarem de conhecimentos que potencializaram melhores condições de dinamizar, de forma segura, as estratégias formativas. Destacaram ainda que se tratou de uma medida capaz de favorecer aos formadores a apropriação, com autonomia, dos Cadernos de Formação.

Para os formadores, esses Cadernos representaram um caminho capaz de conduzir a construção ou a efetivação de conhecimentos indispensáveis ao professor alfabetizador. Assim, conforme mencionado anteriormente, extrapolaram o entendimento indicado por alguns pesquisadores de serem instrumentos a serviço de uma orientação curricular (LUZ, 2017; FERREIRA e FONSECA, 2017; PEREIRA, 2017). Entretanto, afirmaram que, por serem densos, para serem apropriados e trabalhados de modo autoral na formação, como era esperado por algumas universidades, dentre elas a mencionada no excerto de Aline, exigia-se uma base de conhecimentos sólidos por parte do formador. 
Interessante também destacar que os formadores entrevistados afirmaram que o PNAIC representou condições de desenvolvimento profissional. Afirmaram que, sobretudo as reuniões de estudo, estudos individuais para as reuniões, troca com seus pares formadores e com os OEs, acarretaram aprofundamento, revisão e construção de conhecimento. Assim, esse processo se constituiu como um momento de autoformação para os formadores.

No entanto, afirmaram acreditar que, para alguns OEs e PAs, o programa parece ter se consolidado como uma formação de caráter compensatório. Desse modo, entendem que longe de ser o ideal, porém, diante da incapacidade de a formação inicial ter favorecido a construção de saberes basilares para os que atuarão na docência, formações como o PNAIC têm lugar central, vez que representam uma oportunidade de se propiciar uma base de conhecimentos imprescindíveis a todos os professores alfabetizadores do território brasileiro.

Assim, considerando a constatação de Soares $(2014,2016)$ sobre a falta de uma formação capaz de fundamentar um trabalho com as práticas do que se ensina, quando se ensina a língua escrita e como se ensina, programas de formação em rede, sobretudo pela abrangência, podem ser uma ação que implica a ressignificação das estratégias pedagógicas adotadas, de modo a conduzir as crianças a uma aprendizagem bem-sucedida da leitura e da escrita (SOARES, 2016).

No entanto, cabe esclarecer que os formadores não defendem os momentos instituídos para a formação continuada como sendo de caráter compensatório. No diálogo com eles, fica claro que defendem a luta constante pela revisão da formação inicial e pela consolidação de uma formação continuada como parte de um processo permanente do desenvolvimento profissional. Entretanto, durante esse movimento de reconfiguração do processo formativo, não cabe ao professor atuar no vazio. Desse modo, entendem que, como uma saída emergencial, pode ser que a formação continuada aconteça com esse preceito de compensar as deficiências do momento inicial formativo não realizado a contento. Ainda sobre as considerações que os formadores apresentaram na condução do PNAIC no âmbito das universidades, o grupo destacou a importância da forma como a instituição acolheu os saberes construídos pelos professores da Educação Básica. A respeito disso, a maioria que atuou no PNAIC, especialmente em seus primeiros anos de implementação, relembrou que tiveram que assumir uma postura de "enfrentamento" a algumas condutas e estratégias indicadas pela coordenação. Muitas vezes sentiam seus conhecimentos "abafados" diante dos acadêmicos. Com efeito, afirmaram que houve embates e uma "certa" pressão para que o desenho do programa ganhasse contornos que garantissem a articulação dos conhecimentos acadêmicos aos do campo escolar.

Com base nessa afirmação, é possível inferir que um grupo de formadores com conhecimentos sólidos construídos no campo acadêmico e no campo experiencial foi fundamental para essa equipe ter argumentos e segurança na busca por romper com a tradição de valorização no campo formativo dos conhecimentos teóricos em detrimento dos construídos no campo de atuação. A fala da coordenadora adjunta reforça isso:

Desde o início havia uma intensa preocupação com a prática, embora no início não se tenha construído estratégias que a favorecessem. No início havia uma preocupação em seguir os Cadernos, um tom mais de prescrição. Depois fomos amadurecendo e ganhando autonomia. Fomos abrindo mais espaço para o diálogo com a prática (...) A equipe foi analisando e encontrando a medida para a formação. E aí nesse ponto foi muito bom ter uma equipe " 5 estrelas" que contava com formação acadêmica e atuação profissional. Ela tinha muito a dizer (CRISTIANE - coordenadora adjunta do PNAIC pela UFJF).

Importante destacar que os formadores acreditaram que, caso não tivessem assumido a postura de "enfrentamento", pode ser que as críticas acadêmicas referentes ao mau uso do programa, denotando a ele um tom meramente prescritivo, relacionado com accountability e na culpabilização e desqualificação da docência do sistema público de ensino (LUZ, 2017; FERREIRA e FONSECA, 2017; PEREIRA, 2017), tomassem força na instância em que atuaram dando um outro tom ao programa de formação.

Considerando o contexto apresentado pelos formadores, interessante mencionar que a implementação da proposta formativa foi operacionalizada a partir de embates para se chegar a uma unidade consensual. Essa realidade evidenciou que, diante de uma política intencionada para se calcarem 
determinados objetivos, há uma força capaz de alterar o planejado. Nesses termos, conforme mencionou Ball (2015), a apropriação dos sujeitos faz com que as políticas, embora tenham uma base de proposição estrutural, têm os sentidos alterados pelos sujeitos que a implementam.

No âmbito da gestão local dos sistemas pactuados, os entrevistados observaram o descaso com medidas importantes para se garantir o sucesso do programa. Destacaram a falta de compromisso de algumas redes com questões de sua competência, como a garantia de custeios das despesas de deslocamento, alimentação e hospedagem para os momentos de formação das OEs junto à IES. Ainda por parte da "quebra" de compromisso no contexto dos sistemas de ensino, a maioria dos formadores mencionou a falta de comprometimento na indicação de OEs e CLs. Os entrevistados afirmaram que muitos gestores pareciam ter tomado como base uma questão pessoal em detrimento da profissional, descumprindo as exigências do MEC quanto à designação desse quadro de formadores da rede estabelecida pelo PNAIC.

Em geral, observou-se que, em alguns municípios, foram indicados professores sem experiência docente na alfabetização. Em decorrência dessa situação, os formadores entrevistados afirmaram que, além de terem que lidar com professores com pouco conhecimento sobre o ato de alfabetizar em virtude da precária formação inicial que recebem, tiveram que lidar também com profissionais que tinham muito pouco ou nenhum envolvimento com o campo escolar, especificamente com a alfabetização. Frente a esse cenário, boa parte dos formadores sinalizou a importância de um maior controle sobre os critérios utilizados pelos municípios quanto à seleção de seus representantes. Caso contrário, como ocorreu em alguns contextos em algumas localidades, ficam afetadas a mobilização e a credibilidade do programa, o que poderia diminuir sua possibilidade de se realizar como uma ação formativa que, de fato, possa alterar as práticas escolares.

Por fim, retomaram a discussão sobre o compromisso dos municípios em constituir a formação de rede, permitindo aos PAs condição de aprofundarem e reconstruírem novos saberes. A coordenadora geral da UFJF reforçou a importância dessa ação, ao afirmar que "o PNAIC não veio para se impor as realidades locais Brasil afora, ao contrário, para disparar um movimento nessas realidades de modo a fomentar a formação de rede" (JANAÍNA - coordenadora geral do PNAIC pela UFJF).

Da forma como os dados se apresentam, é possível arriscar que, talvez, a expectativa de que o programa mobilizasse um intenso movimento ao direito de todos os professores a uma formação continuada voltada às suas realidades locais tenha sido uma das principais motivações dos agentes formativos que atuaram no âmbito da UFJF. De fato, eles acreditaram que empoderar as esferas locais, por meio dos OEs, poderia implicar a institucionalização da formação em rede e de rede. No entanto, lamentaram que a efetivação desse preceito se apresentou como um dos maiores desafios postos ao programa.

\section{CONSIDERAÇÕES FINAIS}

O objetivo perseguido ao longo do presente artigo foi o de analisar os limites e as possiblidades de uma formação em rede. Para tanto, com base nas entrevistas realizadas com agentes formativos de um programa de formação em larga escala, pretendeu-se dar visibilidade ao campo da apropriação desses agentes. Os dados corroboram o que estudos, como os realizados pelo sociólogo inglês Stephen Ball e colaboradores, como Bowe, apresentados no Brasil por pesquisadores, como Mainardes (2006), indicam: o poder de condução dos sujeitos influencia os resultados de uma política. Desse modo, ainda que o contexto de produção do discurso do PNAIC tenha sido realizado no âmbito do MEC de modo a cumprir uma agenda empresarial deliberada pelo Movimento Todos pela Educação, ao que parece, a implementação foi recontextualizada. Ao colocar a formação em ação, os formadores das universidades reconstruíram estratégias e reorganizaram o trabalho com os Cadernos de Formação, de maneira a contemplar a teorização da prática e, assim, conduziram a formação de modo a modificar possíveis interesses do discurso oficial em um discurso pedagógico mais próximo da realidade das escolas. 
Os dados analisados permitiram compreender que os entrevistados revelaram que ter trazido a oportunidade de integrar à universidade o professor com o crivo da experiência favoreceu a possibilidade de se alterar o modelo comumente praticado no processo formativo, impactando um movimento de parceria entre a universidade e a escola de Educação Básica. Nesses termos, pode-se afirmar que tendo o programa se consubstanciado como um elemento importante para descontruir a disputa em espaços hierarquicamente demarcados, criou caminho para o diálogo entre a pesquisa acadêmica e a escola, situação tão esperada pelos estudiosos do campo da formação docente (GATTI, BARRETO, ANDRÉ, NÒVOA, CÁNARIO, VAILLANT). No contexto dessa dinâmica, os formadores se reconheceram como figuras centrais. Afirmaram perceber que, por meio dos embates que sustentaram, criaram possibilidades para que a formação tivesse um desenho pautado na praxiologia (GATTI, 2013).

No geral, foi possível observar um processo marcado por uma predisposição comum de buscar a "zona de escape" e, portanto, delineado por possibilidades de deslizamentos de alguns preceitos atravessadores da política central que pudessem remetê-la a mecanismos de culpabilização individual do professor pelos resultados aferidos em avaliações externas, como é a preocupação de muitos pesquisadores diante do cenário das atuais políticas educacionais (FREITAS, 2012; DICKEL, 2016; LUZ, 2013, 2017; ROCHA et al. 2014).

Com efeito, é possível afirmar que, ainda que muitos limites precisem ser superados, em especial os relacionados a aspectos como problemas estruturais referentes à força das ingerências políticas nas diferentes instâncias da rede formativa; distância entre os formadores que atuaram pela UFJF e os professores alfabetizadores; dificuldade de viabilização da formação de rede e, ainda, referentes à atuação dos formadores, que foram os principais responsáveis por traduzirem a política formativa, o PNAIC se desdobrou como uma política que buscou viabilizar estratégias para que os PAs tivessem a oportunidade de construir conhecimentos capazes, de fato, de reverberar ações pedagógicas voltadas ao direito de aprendizagem de todos os alunos.

Por tudo, os agentes formativos demonstraram que o ideário de Freire (1984) parece se repetir, despertando a esperança de que, por meio de suas práticas, pudessem "modificar realidades". Desse modo, o desejo que marcou o encontro da maioria do grupo de formadores com o magistério, aspecto mencionado anteriormente, corporificou-se nos seus modos de realizar a formação. O depoimento de Alessandra resume a dimensão desse compromisso diante do PNAIC e, por conseguinte, diante dos seus pares:

A gente tinha esperança na formação. A gente chegou com muito amor pela profissão e com vontade de ajudar a escola. Era um grupo comprometido com o programa. Comprometidos em dar condição para as professoras ensinarem (ALESSANDRA - formadora de MT pela UFJF).

Fica assim o desejo de que esse compromisso inspire um número maior de profissionais envolvidos com o ensino e dê frutos aos sistemas educacionais brasileiros.

\section{REFERÊNCIAS}

ANDRÉ, Marli, E. D. A. Políticas de Valorização do trabalho docente no Brasil. Revista Ensaio: avaliação e políticas públicas em educação, vol. 23, n. 86. Rio de Janeiro, jan./ fev. 2015.

ALFERES, Marcia Aparecida; MAINARDES, Jefferson. A recontextualização do Pacto Nacional pela Alfabetização na Idade Certa - PNAIC: uma análise dos contextos, macro, meso e micro. Revista Currículo sem Fronteiras, v. 18, n. 2, p. 420-444, maio/ago. 2018. Disponível em: http://www.curriculosemfronteiras.org/vol18iss2articles/alferes-mainardes.html. Acesso em: 02 nov. 2018. 
. O Pacto Nacional pela Alfabetização na Idade Certa em ação: revisão de literatura. Revista Ensaio: avaliação e políticas públicas em educação, Rio de Janeiro, ahead of print, Epub 29-Out-2019. Disponível em: http://dx.doi.org/10.1590/s0104-40362018002601262. Acesso em: 02 nov. 2018.

BALL, Stephen J. [2015]. Olhares. Guarulhos, v. 3, n. 2, p. 161-171. Entrevista concedida a MAINARDES, Jefferson. Tradução de Janete Bridon. 2015.

BARDIN, Laurence. Análise de Conteúdo. Lisboa, Portugal; Edições 70, LDA, 2009.

BRASIL. Portaria $n^{\circ} 1.458$, de 14 de dezembro de 2012a. Define categorias e parâmetros para a concessão de bolsas de estudo e pesquisa no âmbito do Pacto Nacional pela Alfabetização na Idade Certa, na forma do art. $2^{\circ}$, inciso I, da Portaria MEC n ${ }^{\circ} 867$, de 4 de julho de 2012. Diário oficial [da] República Federativa do Brasil, Poder Executivo, Brasília, DF, 15 dez 2012c. Disponível em: $<$ http://pacto.mec.gov.br/images/pdf/port_1458_141212.pdf>. Acesso em: 22 ago. 2016.

. Portaria no 867, de 4 de julho de 2012b. Institui o Pacto Nacional pela Alfabetização na Idade Certa e as ações do Pacto e define suas diretrizes gerais. Diário oficial [da] República Federativa do Brasil, Poder Executivo, Brasília, DF, 5 jul 2012. Disponível em: < http://pacto.mec.gov.br/images/pdf/port_867_040712.pdf>. Acesso em: 20 ago.2016.

Lei no. 9.394/96, de 20 de dezembro de 1996. Estabelece Diretrizes e Bases para a Educação Nacional. Diário Oficial da República Federativa do Brasil. Brasília, DF, 23 dez. 1996.

. Secretaria de Educação Básica. Diretoria de Apoio à Gestão Educacional. Pacto nacional pela alfabetização na idade certa: formação de professores no pacto nacional pela alfabetização na idade certa. Caderno de Apresentação Brasília: MEC, 2015.

. Ministério da Educação. Guia Geral do Pró-Letramento. Brasília, 2007b.

Decreto n. 6.094, de 24 de abril de 2007. Dispõe sobre a implantação do Plano de Metas Compromisso Todos pela Educação, pela União Federal, em regime de colaboração com Municípios, Distrito Federal e Estados, e a participação das famílias e da comunidade, mediante programas e ações de assistência técnica e financeira, visando à mobilização social pela melhoria da qualidade da educação básica. Diário Oficial da União. Brasília, DF, 24 de abril de 2007a.

Secretaria de Educação Básica. Diretoria de Apoio à Gestão Educacional. Pacto nacional pela alfabetização na idade certa: formação de professores no pacto nacional pela alfabetização na idade certa. Caderno de Apresentação Brasília: MEC, 2015.

. Ministério da Educação. Portaria n. 826, de 7 de julho de 2017. Dispõe sobre o Pacto Nacional pela Alfabetização na Idade Certa - PNAIC e suas ações, diretrizes gerais e a ação de formação no âmbito do Programa Novo Mais Educação - PNME. Brasília, 7 de julho de 2017. Disponível em: http://www.lex.com.br/legis_27464570_PORTARIA_N_826_DE_7_DE_JULHO_DE_2017.aspx. Acesso em: 29 dez. 2017.

Portaria MEC n 155, de 22 de março de 2016b. Altera a Portaria MEC no 1.458, de 14 de dezembro de 2012, que define categorias e parâmetros para a concessão de bolsas de estudo e pesquisa no âmbito do Pacto Nacional pela Alfabetização na Idade Certa. Diário oficial [da] República Federativa do Brasil, Poder Executivo, Brasília, DF, 23 mar 2016b. Disponível em: $<$ http://pacto.mec.gov.br/images/portarias/Portaria_155.pdf>. Acesso em: 24 ago. 2016.

BRZEZINSKI, Iria. Políticas Contemporâneas de formação de professores para os anos iniciais do ensino fundamental. Revista Educação e Sociedade. Campinas, SP, v. 29, n. 105, p. 1139-1166, set./dez. 2008.

Disponível em: 
http://www.scielo.br/scielo.php?pid=S010173302008000400010\&script=sci_abstract\&tlng=pt. Acesso em: 04 jul. 2016.

CANÁRIO, Rui. A experiência portuguesa dos Centros de Formação das Associações de Escola. IN: MARIN, Alda Junqueira. Educação Continuada: reflexões, alternativas. 2 ed. Campinas, SP: Papirus, 2004, p. 63-88.

. A escola tem futuro? Das promessas às incertezas. Porto Alegre: Artmed, 2006, 160p.

CANDAU, Vera Maria (org.). Universidade e Formação de Professores: que rumos tomar? Magistério: construção cotidiana. Petrópolis, Rio de Janeiro: Vozes, 2003.

CRUZ, Giseli Barreto da. Ensino de didática e aprendizagem da docência na formação inicial de professores. Caderno de Pesquisa. São Paulo, v. 47, n. 166, p. 1166-1195, dez. 2017. Disponível em http://dx.doi.org/10.1590/198053144323. Acesso em 14 jan. 2018.

DICKEL, Adriana. A Avaliação Nacional da Alfabetização no Contexto do Sistema de Avaliação da Educação Básica e do Pacto Nacional pela Alfabetização na Idade Certa: responsabilização e controle. Cadernos Cedes, Campinas, v. 36, n. 99, p. 193-206, maio-ago. 2016.

FERREIRA, Patrícia de Faria; FONSECA, Marcia Souza da. Profissionalismo Docente e a Formação Matemática do Pacto Nacional pela Alfabetização na Idade Certa. In: Encontro Brasileiro da Redestrado. Campinas, 2017 (comunicação oral).

FREIRE, Paulo. Educação: o sonho possível. IN: BRANDÃO, Carlos Rodrigues (org.). O Educador: vida e morte. Rio de Janeiro: Graal, 1984.

Pedagogia da Autonomia: saberes necessários à prática educativa. São Paulo: Paz e Terra, 1996. (Coleção Leitura).

FREITAS, Luiz Carlos de. Os reformadores empresariais da educação: da desmoralização do magistério à destruição do sistema público de educação. Sociedade e educação. Campinas, v.33, n. 119, 2012.

FONSECA, Claudia. Quando cada caso NÃO é um caso: pesquisa etnográfica e educação. Revista Brasileira de Educação, n.10, p. 58-78. 1999.

GATTI, Bernardete Angelina; BARRETO, Elba de Sá, ANDRÉ, Marli. Políticas docentes no Brasil: um estado da arte. Brasília: UNESCO, 2011.

; BARRETO, Elba de Sá. (Coords.). Professores do Brasil: impasses e desafios. Brasília: UNESCO, 2009.

GATTI, Bernardete Angelina. Educação, escola e formação de professores: políticas e impasses. Educar em Revista. Curitiba, n. 50, p. 51-67. Out./dez. 2013.

Formação de Professores no Brasil: características e problemas. Educação e Sociedade. Campinas, SP, v. 31, n. 113, p. 1355-1379. Out. - dez. 2010.

- Análise das políticas públicas para a formação continuada no Brasil, na última década. Revista Brasileira de Educação. Campinas, SP, v. 13, n. 37, p. 57-186. Jan./abr. 2008. 
GELOCHA, Elizandra Aparecida Nascimento; CORTE, Marilene Gabriel Dalla. Pacto Nacional pela Alfabetização na Idade Certa e Formação de Professores: o que dizem as produções científicas? Educação por Escrito. Porto Alegre, RS, v. 7, n. 1, p. 106-123, jan-jun. 2016.

LUZ, Iza Cristina Prado da; FERREIRA, Diana Lemes. Pacto Nacional Pela Alfabetização Na Idade Certa: Formação, Avaliação e Trabalho Docente em Análise. Revista Brasileira de Políticas e Administração da Educação, v. 29, n. 3. Set./dez. 2013.

- Pacto Nacional da Alfabetização na Idade Certa (PNAIC): A Política de Formação Continuada de Professores e a Legislação Educacional em Análise. In Encontro Brasileiro da Redestrado. Apresentação oral. 2017.

MAINARDES, Jefferson. Abordagem do Ciclo de Políticas: uma contribuição para a análise de políticas educacionais. Revista Educação e Sociedade, Campinas, n.94, p. 47-69, jan./abr. 2006.

NÓVOA, António. Concepções e práticas de formação contínua de professores. In: Congresso Nacional de Formação Continuada de Professores: realidades e perspectivas. Aveiro, Anais... Aveiro: Universidade de Aveiro, 1991. p. 15-18.

OLIVEIRA, Leandra Martins de. Políticas educacionais na formação de professores dos anos iniciais do Ensino Fundamental em cursos de licenciatura. Revista Ensaio: Avaliação e Políticas Públicas em Educação. Fundação CESGRANRIO. Rio de Janeiro, v. 18, n. 67, p. 235-252, abr./jun. 2010.

PEREIRA, Viviane Carrijo Volnei. Formação Continuada de Professores Alfabetizadores e as Concepções de Formação no Pacto Nacional pela Alfabetização na Idade Certa (PNAIC). In: Redestrado. 2017. (Apresentação Oral).

RINALDI, Renata Portela. Desenvolvimento profissional de formadores da educação básica: uma experiência envolvendo a parceria universidade-escola. 35a reunião da ANPED. 2012. Disponível em: http://35reuniao.anped.org.br/images/stories/trabalhos/GT08\%20Trabalhos/GT082473_int.pdf.

Acesso em: 2 dez. 2016.

ROCHA, Sônia Cláudia Barroso da; Bissoli, Michelle de Freitas; BOTELHO, Arminda Rachel de. Pacto Nacional pela Alfabetização na Idade Certa como uma Política de Formação Docente do Estado de Concepção Neoliberal. II Congresso Nacional de Formação de Professores. XII Congresso Estadual Paulista sobre Formação de Educadores. 2014. Disponível em: http://unesp.br/anaiscongressoeducadores/ArtigoVisualizar?nome_arquivo=http://200.145.6.217/pr oceedings_arquivos/ArtigosCongressoEducadores/703.pdf. Acesso em: 24 nov. 2017.

SOARES, Magda. Formação de rede: uma alternativa de desenvolvimento profissional de alfabetizadores/as. Cadernos Cenpec. São Paulo, v. 4, n. 2, p. 146-173. Dez. 2014.

. Alfabetização: a questão dos métodos. São Paulo: Contexto, 2016.

TARDIF, Maurice; LESSARD, Claude. Saberes Docentes e Formação Profissional. Petrópolis: Vozes, 2002.

VAILLANT, Denise. Formação de formadores. Fundação Victor Civita, Oficio de professor na América Latina e Caribe: Trabalhos apresentados na Conferência Regional "O Desempenho dos professores na América Latina e no Caribe: Novas prioridades"- Brasília. 2002. 


\section{NOTAS}

${ }^{1}$ Aprovada pelo Comitê de Ética de Pesquisa com Seres Humanos da instituição em que a pesquisa se desenvolve conforme parecer número 1.715 .141$.

2 A partir de 2016, o PNAIC sofreu alterações significativas em sua estrutura (BRASIL, 2017). Os dados que alimentam este artigo consideram o formato inicial da proposta, ou seja, as orientações previstas no decorrer dos anos de 2013 a 2016.

${ }^{3}$ De acordo com a portaria $n^{\circ}$. 1.458, de 14 de dezembro de 2012 (Brasil, 2012a), substituída em 2016 pela Portaria no. 155/2016 (Brasil, 2016b), é prevista a concessão de bolsas do FNDE para estudo e pesquisa à equipe de atuação no PNAIC. ${ }^{4}$ Considerando o ano de 2012 em que a UFJF implementou o PNAIC como uma das instituições pioneiras nessa formação. ${ }^{5}$ Com base nos documentos orientadores, a partir de 2017, passou a ser semipresencial (BRASIL, 2017).

${ }^{6}$ O Pró-Letramento é um programa governamental de formação continuada e em serviço destinado aos professores das séries iniciais do Ensino Fundamental, que atuam na rede pública de ensino, com o objetivo de favorecer a melhoria do desempenho escolar de alunos nas áreas de leitura/escrita e matemática. Foi implementado em 2005, por meio da Secretaria de Educação Básica e da Secretaria de Educação a Distância, em parceria com universidades que integram a Rede Nacional de Formação Continuada e com a adesão das secretarias estaduais e municipais de educação mediante ao Plano de Ações Articuladas (BRASIL, 2007b).

${ }^{7}$ Destaca-se que, neste trabalho, o preceito de qualidade da educação é pautado na concepção de qualidade social apresentada por Brzezinski (2008).

${ }^{8}$ Com o objetivo de preservar a identidade dos entrevistados, todos os nomes dos entrevistados são fictícios.

${ }^{9}$ Refere-se a uma instituição pública municipal, vinculada à Secretaria de Educação do município de Juiz de Fora, que garante o atendimento especializado a crianças e jovens da rede municipal de Juiz de Fora que enfrentam barreiras na aprendizagem. ${ }^{10}$ A referida formadora atuou tanto na área de LP quanto de MT. Fez isso em anos diferentes, ou seja, em uma formação compôs o grupo de formadores de LP e, depois, o grupo de MT.

Submetido: $01 / 10 / 2018$

Aprovado: 06/04/2020

Contato:

Luciana Castro Oliveira Machado

Rua Ivon José Curi, 355. Portal da Torre Juiz de Fora |MG|Brasil

CEP 36037467 